\title{
Forward masking and cognitive-language skills in children as a function of literacy stage
}

\author{
Nathália Hollanda da Fonsêca ${ }^{1}$ \\ https://orcid.org/0000-0002-3351-6172 \\ Bianca Arruda Manchester de Queiroga ${ }^{1}$ \\ https://orcid.org/0000-0001-5081-924X \\ Ana Cristina de Albuquerque Montenegro ${ }^{1}$ \\ https://orcid.org/0000-0001-5791-0900 \\ Pedro de Lemos Menezes ${ }^{2}$ \\ https://orcid.org/0000-0003-1999-5055 \\ Denise Costa Menezes ${ }^{1}$ \\ https://orcid.org/0000-0002-2008-4091 \\ Silvana Maria Sobral Griz ${ }^{1}$ \\ https://orcid.org/0000-0002-6759-5964
}

Universidade Federal de Pernambuco UFPE, Recife, Pernambuco, Brasil.

2 Universidade Estadual de Ciências da Saúde em Alagoas, Maceió, Alagoas, Brasil

Conflict of interests: Nonexistent

\section{(c) (i)}

Received on: October 11, 2021

Accepted on: November 8, 2021

Corresponding address:

Denise Costa Menezes

Avenida Prof. Moraes Rego, 1235 -

Cidade Universitária

CEP: 50670-901 - Recife, Pernambuco, Brasil

E-mail: denize.menezes@ufpe.br.com

\section{ABSTRACT}

Purpose: to investigate the relation between forward masking and cognitive-language skills in children as a function of literacy stage.

Methods: twenty-seven children registered in literacy stage at public schools, aged from 6 to 9 years old, with no learning difficulties or audiological problems reported, participated in this study. Frequency Following Responses were registered in two test conditions: 1) /da/ alone; 2) /da/ presented 4 milliseconds after a speech noise. Two language protocols were applied: a cognitive-linguistic skills protocol and a phonological awareness one.

Results: forward masking was evident in Frequency Following Responses of all children regardless of literacy stage. Frequency Following Responses latencies in both testing conditions showed no difference among participants' age. Cognitive-language skills scores were below those expected for all children, with significant improvement noticed as a function of age. No correlation between language performance and forward masking was found.

Conclusion: there was no relation between forward masking and cognitive-language skills in children, as a function of literacy stage.

Keywords: Evoked Potentials, Auditory, Brainstem; Noise; Speech; Child Language; Cognition 


\section{INTRODUCTION}

Auditory processing is a complex neural function related to how the auditory system processes acoustic information ${ }^{1}$. In order to process speech sounds, the ability to perceive temporal changes of the type of stimulus is required from the auditory system, especially in unfavorable listening situations ${ }^{1}$. On the other hand, temporal processing difficulties may change auditory perception of speech ${ }^{2,3}$, which can lead to problems in language development.

Hearing plays an essential role in language development, especially in the phonological acquisition of a language, and speech processing. From the auditoryperceptual perspective, one learns how to discriminate speech sounds and organize their patterns into appropriate categories ${ }^{4}$. The ability to identify phonological contrasts occurs throughout child's development until approximately seven years of age $e^{4,5}$.

During literacy stages, children with typical development may face difficulties in listening situations, especially at school. Many classrooms are noisy, and factors such as competitive noise, distance between teachers and sounds reverberation may interfere in appropriately perceiving the target speech and, in turn can result in low academic performance ${ }^{6}$.

Auditory difficulties, including distorted temporal perception, increase chances for phonological processing disorders and learning problems. Specifically, it may also result in difficulties on the literacy process ${ }^{7,8}$.

Temporal auditory processing refers to the ability of the auditory system to process characteristics of the temporal changes of a sound ${ }^{1}$, and includes abilities such as temporal ordering, temporal integration, temporal resolution and temporal masking ${ }^{9,10}$. Temporal masking occurs when a sound threshold is increased by the presence of another sound with higher intensity, which can be simultaneous or not simultaneous. In simultaneous masking, the masking sound occurs at the same period of time as the target sound. Non simultaneous masking ca occur before (forward masking) or after (backward masking) the target sound. When a masking sound is able to mask a previous target sound, this is called backward masking. When a masking sound is able to mask a subsequent target sound, this is called forward masking; this is to say that that masking happens after the masking sound has been ceased or its intensity has been reduced ${ }^{11-13}$.

Considering that: (i) hearing plays a significant role in oral language development during the literacy period, and (ii) background noise can interfere in auditory information processing, the goal of this study was to investigate the relation between forward masking and cognitive-linguistic skills in children as a function of literacy stage. Forward masking was observed on Frequency Following Responses (FFR) by presenting a speech stimulus alone and a speech stimulus presented four milliseconds after noise. Correlation testing between forward masking values and phonological awareness and cognitive-language skills findings were performed.

\section{METHODS}

This research was approved by the Ethical Committee in Research on Human Beings of the Federal University of Pernambuco, Brazil, and registered under the number 02660712.8.0000.5208.

Participants included twenty-seven $(n=27)$ children aging from 6 to 9 years-old, enrolled to $1^{\text {st }}, 2^{\text {nd }}$ and $3^{\text {rd }}$ grades of Elementary Public School. They were divided into three groups: ten $(n=10)$ were at the $1^{\text {st }}$ grade, seven $(n=7)$ at the $2^{\text {nd }}$ grade, and ten $(n=10)$ at the $3^{\text {rd }}$ grade. All participants presented no learning disabilities reported by teachers, pure-tone audiometric thresholds $\leq 15 \mathrm{~dB} \mathrm{HL}$ and type A tympanograms on both ears.

Data was collected by using: (a) Frequency following responses (FFR) to a synthetic syllable /da/, with and without the presence of a speech-shaped noise (SSN); (b) CONFIAS questionnaire (Phonological Awareness: Instrument for Sequential Evaluation) ${ }^{14}$; (c) Protocol for Cognitive-Linguistic Skills ${ }^{15}$; and (d) semi-structured socioeconomic questionnaire.

FFR was performed under two conditions: (i) /da/ alone and (ii) /da/ presented $4 \mathrm{~ms}$ after the SSN.

The FFR protocol under both conditions was as follows: 70 ms window; gain at 100,000; $50 \mathrm{~Hz}$ high-pass filter and $3000 \mathrm{~Hz}$ low-pass filter; stimulus rate at $3.77 / \mathrm{sec}$; alternating polarity; monoaural presentation at right ear. Two or more traces of 2000 sweeps were performed, and a final trace of 4000 sweeps was obtained by the sum of two reproduceable traces.

FFR at the condition without noise were performed with the /da/ syllable presented at a fixed intensity of $75 \mathrm{~dB}$ SPL. For the noise condition, the /da/ syllable was presented 4 milliseconds after a 100 milliseconds speech-shaped noise (SSN). The /da/ syllable was produced by Kraus ${ }^{1}$. The speech noise was produced at the Hearing Science Laboratory at the University of North Carolina at Chapel Hill. It contains a speech spectrum of the Brazilian Portuguese, 10 milliseconds 
rise and fall-time, and was presented at $80 \mathrm{~dB}$ SPL. For both conditions, latencies of the waves PV, A, PW, PX, $P Y, P Z$ and $O$ were identified and analyzed ${ }^{12}$.

FFR latency analysis was performed by identifying waves $\mathrm{PV}$ and $\mathrm{A}$ (corresponding to the transient portion of response /d/) and waves PW, PX, PY and PZ (corresponding to the sustained portion of the response /a/) and wave $O$ (corresponding to the response offset) were marked (Figure 1).

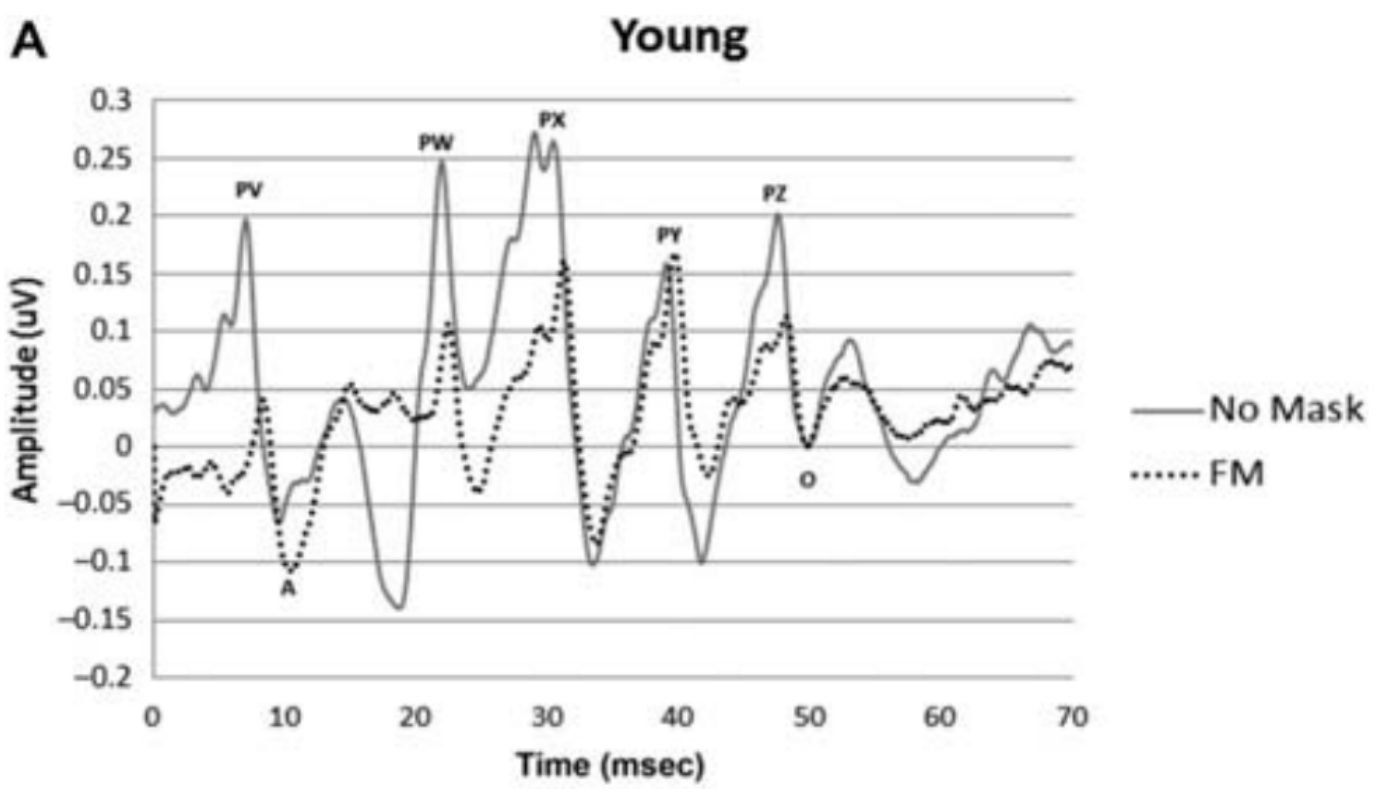

Captions: FM - Forward Masking

Figure 1. Frequency Following Responses latencies in both tested conditions, in silence and in noise

The CONFIAS protocol was performed in two parts: at syllable level and phoneme level. The results were processed by the sum of these two parts: $\mathrm{CFS}=$ syllables, CFF $=$ phonemes and CFT $=$ total.

The collective version of the Cognitive-Linguistic Skills protocol was applied, consisting on six subtests: writing the alphabet in sequence (ESCALF), shape copying (COPFOR), mathematical calculation (CALMAT), word dictation writing (DITPAL) and pseudo words (DITPSEU), and number repetition (REPNU).

Kolmogorov-Smirnov Test of Normality was applied to determine normality of data. Mean and standard deviation of latencies waves were identified and a t-Test was used to identify significant differences between FFR latency of both test conditions.

Forward masking was considered by latency difference between FFR among test conditions. ANOVA and Tukey's test were used in order to investigate forward masking in each year of literacy stage, and to verify presence of significant difference between test conditions for each FFR latency. ANOVA was also applied to compare latency values among years of literacy stage.

Descriptive analysis of the data was performed to investigate development of cognitive-linguistic skills as a function of literacy stage. ANOVA and Tukey's tests were applied to compare data among literacy stage and to obtain significance level, respectively. Pearson's correlation test was used to carry out correlation between FFR findings with cognitive-language skills findings. All analyzes were considered at $95 \%$ confidence interval to determine significance $(p<0.05)$.

\section{RESULTS}

For FFR latency analysis, Table 1 shows FFR mean latencies of all children $(n=27)$, according to the test condition ('without masking - NM' and with masking $4 \mathrm{~ms})$. 
Table 1. Frequency Following Responses latencies according to test condition

\begin{tabular}{|c|c|c|c|c|}
\hline \multirow{3}{*}{ FFR waves } & \multicolumn{2}{|c|}{ Test Condition } & \multirow{3}{*}{$\begin{array}{l}\text { Mean Difference } \\
\text { ms }\end{array}$} & \multirow{3}{*}{$P$ Value } \\
\hline & Without masking & With masking 4ms & & \\
\hline & \multicolumn{2}{|c|}{$\begin{array}{c}\text { Mean } \pm \text { SD } \\
\mathrm{ms}\end{array}$} & & \\
\hline PV & $6.97 \pm 0.39$ & $7.99 \pm 0.50$ & 1.02 & $\mathrm{p}<0.001^{*}$ \\
\hline A & $8.44 \pm 0.71$ & $9.64 \pm 0.57$ & 1.2 & $\mathrm{p}<0.001^{*}$ \\
\hline PW & $21.56 \pm 0.76$ & $22.22 \pm 0.72$ & 0.66 & $p<0.001^{*}$ \\
\hline PX & $30.22 \pm 0.54$ & $30.91 \pm 0.84$ & 0.69 & $p<0.001^{*}$ \\
\hline PY & $39.17 \pm 0.64$ & $39.71 \pm 0.74$ & 0.54 & $p<0.001^{*}$ \\
\hline $\mathrm{PZ}$ & $47.50 \pm 0.57$ & $48.12 \pm 0.74$ & 0.62 & $p<0.001 * *$ \\
\hline 0 & $48.82 \pm 0.75$ & $49.47 \pm 0.92$ & 0.65 & $p<0.001 *$ \\
\hline
\end{tabular}

$\left.{ }^{\star}\right)$ : Significant difference considering $95 \%$ confidence interval using Student's t-test

$(* \star)$ : Significant difference considering $99 \%$ confidence interval using Student's t-test

Captions: PV, A, PW, PX, PY, PZ, 0 - Positive and Negative Peaks of Frequency Following Responses

All mean latencies were significantly higher for masking condition as compared to no masking condition. Marked latency delay was found for waves corresponding to the transient portion of the response, suggesting greater forward masking in this region, when compared to the sustained portion.

Table 2 describes FFR wave latencies for all children as a function of years of the literacy stage.

Table 2. Frequency Following Responses latencies (ms) as a function of literacy stage $(\mathrm{N}=27)$

\begin{tabular}{|c|c|c|c|c|c|c|c|c|c|c|c|c|c|c|}
\hline \multicolumn{15}{|c|}{ Test Condition } \\
\hline \multicolumn{8}{|c|}{ Without masking } & \multicolumn{7}{|c|}{ With masking - 4ms } \\
\hline YEAR & PV & A & PW & PX & PY & PZ & $\mathbf{0}$ & PV & A & PW & PX & PY & PZ & 0 \\
\hline 1 & 6.93 & 8.65 & 21.28 & 30.36 & 39.51 & 47.79 & 49.14 & 7.72 & 9.45 & 22.12 & 31.22 & 40.09 & 48.16 & 49.77 \\
\hline 2 & 6.97 & 8.44 & 21.73 & 29.65 & 38.81 & 47.21 & 48.59 & 8.10 & 9.55 & 22.43 & 30.48 & 39.38 & 48.14 & 49.63 \\
\hline 3 & 7.02 & 8.23 & 21.72 & 30.47 & 39.06 & 47.48 & 48.74 & 8.17 & 9.88 & 22.12 & 30.97 & 39.58 & 48.08 & 49.21 \\
\hline $\begin{array}{l}P \text { total } \\
\text { value }(1)\end{array}$ & 0.83 & 0.68 & 0.65 & 0.25 & 0.10 & 0.33 & 0.64 & 0.55 & 0.42 & 0.21 & 0.90 & 0.16 & 0.19 & 0.27 \\
\hline
\end{tabular}

(1): No-significant differences considering the $95 \%$ confidence interval using Anova

Captions: PV, A, PW, PX, PY, PZ, 0 - Positive and Negative Peaks of Frequency Following Responses

No significant difference was observed in FFR latencies among years of the literacy stage.
Table 3 presents comparison of cognitive-linguistic skills responses as a function of literacy stage.

Table 3. Cognitive-linguistic skills response according to literacy stage

\begin{tabular}{|c|c|c|c|c|c|c|c|c|c|}
\hline YEAR & CFS & CFF & CFT & ESCALF & COPFOR & CALMAT & DITPAL & DITPSEU & REPNU \\
\hline 1 & $26.40^{*}$ & $7.60^{*}$ & $34.00^{\star}$ & 22.10 & $3.10^{*}$ & $1.30^{\star}$ & $4.50^{\star}$ & $1.00^{*}$ & $3.30^{*}$ \\
\hline 2 & $23.40^{*}$ & $7.80^{\star}$ & $31.20^{*}$ & 24.00 & $3.30^{*}$ & $3.40^{*}$ & $4.50^{*}$ & $1.20^{*}$ & $5.60 *$ \\
\hline 3 & $35.67^{*}$ & $18.44^{*}$ & $54.11^{*}$ & 26.00 & $3.89 *$ & $7.67^{\star}$ & $21.11^{*}$ & $5.22 *$ & $9.11^{*}$ \\
\hline
\end{tabular}

$\left({ }^{*}\right)$ : Significant difference considering the $95 \%$ confidence interval using Anova with $p$ values $<0.05$

Captions: CFS: value of the syllables part of the CONFIAS protocol; CFF: value of the phonemes part of the CONFIAS protocol; CFT: total value of the CONFIAS protocol; ESCALF: subtest of the Cognitive-Linguistic Skills Protocol regarding writing the alphabet in sequence; COPFOR: subtest of the Cognitive-Linguistic Skills Protocol regarding shape copying; CALMAT: subtest of the Cognitive-Linguistic Skills Protocol regarding mathematical calculation; DITPAL: subtest of the Cognitive-Linguistic Skills Protocol regarding word dictation writing; DITPSEU: subtest of the Cognitive-Linguistic Skills Protocol regarding pseudo words; REPNU: subtest of the CognitiveLinguistic Skills Protocol regarding number repetition. 
There was a significant development $(p<0.05)$ in the students' performances in syllable and phonemic parts of CONFIAS test, as well as in the total score, as a function of school year.

Tukey's test revealed significant differences occurred when first and second years was compared to third year of literacy stage, in syllabic and phonemic parts, and in total score of CONFIAS test $(p<0.05)$.

Despite the significant evolution of students in CONFAS test throughout literacy stage, according to test performance parameters, all children underperformed, except for the third year in syllabic part, achieving desired results. Such significant evolution ( $p$ $<0.05$ ) was also noticed in skills tested by the Protocol for Cognitive-Linguistic Skills, except for alphabet writing, which did not show significant changes across years of literacy stage.

Tukey's test revealed significant differences for shape copying when comparing first and second years $(p<0.05)$, and showed significant differences for mathematical calculation, word dictation, pseudo word dictation and number repetition occurred when comparing first and second years with third year of literacy stage $(p<0.05)$.

According to the applied performance parameters of the Protocol for Cognitive-Linguistic Skills for alphabet writing, all years of literacy stage had superior performance. For shape copying, only the third year had more than half $(80 \%)$ of children with superior performers. For mathematical calculation, all groups were considered with inferior performance. In word dictation, the first and second year underperformed, and the third year had average (50\%) and superior (50\%) performance. In pseudo word dictation, all groups were considered with inferior performance. In number repetition, the first year underperformed, and only the third year outperformed.

Tables 4 and 5 present the correlation matrix of results obtained in FFR assessment, results obtained in CONFIAS and Protocol for Cognitive-Linguistic Skills.

Table 4 shows the correlation of FFR findings with cognitive-linguistic abilities findings in without masking condition.

Table 4. Correlation matrix of cognitive-language skills with Frequency Following Responses without masking

\begin{tabular}{|c|c|c|c|c|c|c|c|c|c|c|c|c|c|c|c|c|}
\hline & PV & A & PW & PX & PY & PZ & 0 & CFS & CFF & CFT & ESCALF & COPFOR & CALMAT & DITPAL & DITSPEU & REPNU \\
\hline PV & 1 & $0.001^{\star}$ & 0.605 & 0.259 & 0.953 & 0.398 & 0.332 & 0.296 & 0.226 & 0.240 & 0.154 & 0.981 & 0.849 & 0.386 & 0.309 & 0.345 \\
\hline A & $0.001^{*}$ & 1 & 0.272 & 0.433 & 0.487 & 0.096 & 0.111 & 0.939 & 0.894 & 0.982 & 0.184 & 0.195 & 0.267 & 0.526 & 0.787 & 0.732 \\
\hline PW & 0.605 & 0.272 & 1 & 0.490 & 0.521 & 0.349 & 0.685 & 0.451 & 0.285 & 0.351 & 0.928 & 0.182 & 0.126 & 0.294 & 0.286 & 0.230 \\
\hline PX & 0.259 & 0.433 & 0.490 & 1 & 0.496 & 0.416 & 0.605 & 0.056 & 0.240 & 0.101 & 0.520 & 0.763 & 0.423 & 0.279 & 0.274 & 0.636 \\
\hline PY & 0.953 & 0.487 & 0.521 & 0.196 & 1 & 0.936 & 0.640 & 0.458 & 0.298 & 0.356 & 0.200 & 0.539 & 0.258 & 0.270 & 0.252 & $0.053^{*}$ \\
\hline $\mathrm{PZ}$ & 0.398 & 0.096 & 0.349 & 0.416 & 0.936 & 1 & $0.000^{*}$ & 0.930 & 0.839 & 0.960 & 0.304 & 0.381 & 0.623 & 0.819 & 0.895 & 0.495 \\
\hline 0 & 0.332 & 0.111 & 0.685 & 0.605 & 0.640 & $0.000^{*}$ & 1 & 0.641 & 0.804 & 0.705 & 0.131 & 0.392 & 0.720 & 0.651 & 0.740 & 0.484 \\
\hline CFS & 0.296 & 0.939 & 0.451 & 0.056 & 0.458 & 0.930 & 0.641 & 1 & $0.000^{*}$ & $0.000^{*}$ & 0.480 & 0.095 & $0.001^{*}$ & $0.000^{*}$ & $0.000^{*}$ & $0.004^{*}$ \\
\hline CFF & 0.226 & 0.894 & 0.285 & 0.240 & 0.298 & 0.839 & 0.804 & $0.000^{*}$ & 1 & $0.000^{*}$ & 0.068 & $0.006^{*}$ & $0.000^{*}$ & $0.000^{\star}$ & $0.000^{*}$ & $0.000^{*}$ \\
\hline CFT & 0.240 & 0.982 & 0.351 & 0.101 & 0.356 & 0.960 & 0.705 & $0.000^{*}$ & $0.000^{*}$ & 1 & 0.206 & $0.024^{\star}$ & $0.000^{*}$ & $0.000^{*}$ & $0.000^{*}$ & $0.000^{*}$ \\
\hline ESCALF & 0.154 & 0.184 & 0.928 & 0.520 & 0.200 & 0.304 & 0.131 & 0.480 & 0.068 & $0.001^{*}$ & 1 & $0.010^{\star}$ & $0.003^{*}$ & $0.003^{*}$ & $0.008^{*}$ & $0.003^{*}$ \\
\hline COPFOR & 0.981 & 0.195 & 0.182 & 0.763 & 0.539 & 0.381 & 0.392 & 0.095 & $0.006^{*}$ & $0.024^{*}$ & $0.010^{*}$ & 1 & $0.000^{*}$ & $0.000^{\star}$ & $0.000^{*}$ & $0.000^{*}$ \\
\hline CALMAT & 0.849 & 0.267 & 0.126 & 0.423 & 0.258 & 0.623 & 0.720 & $0.001^{*}$ & $0.000^{*}$ & $0.000^{*}$ & $0.003^{*}$ & $0.000^{*}$ & 1 & $0.000^{*}$ & $0.000^{*}$ & $0.000^{*}$ \\
\hline DITPAL & 0.386 & 0.526 & 0.294 & 0.279 & 0.270 & 0.819 & 0.651 & $0.000^{\star}$ & $0.000^{*}$ & $0.000^{*}$ & $0.003^{\star}$ & $0.000^{\star}$ & $0.000^{*}$ & 1 & $0.000^{*}$ & $0.000^{*}$ \\
\hline DITPSEU & 0.309 & 0.787 & 0.286 & 0.274 & 0.252 & 0.895 & 0.740 & $0.000^{*}$ & $0.000^{*}$ & $0.000^{*}$ & $0.008^{*}$ & $0.000^{\star}$ & $0.000^{\star}$ & $0.000^{*}$ & 1 & $0.000^{*}$ \\
\hline REPNU & 0.345 & 0.732 & 0.230 & 0.636 & 0.053 & 0.495 & 0.484 & $0.004^{*}$ & $0.000^{*}$ & $0.000^{*}$ & $0.003^{*}$ & $0.000^{*}$ & $0.000^{*}$ & $0.000^{*}$ & $0.000^{*}$ & 1 \\
\hline
\end{tabular}

${ }^{*}$ ): Significant difference considering the $95 \%$ confidence interval using Pearson's correlation test.

Captions: Correlation between Frequency Following Responses and cognitive-language skills; Correlation between CONFIAS and the Protocol for cognitive-linguistic skills; PV, A, PW, PX, PY, PZ, O - Positive and Negative Peaks of Frequency Following Responses; CFS: value of the syllables part of the CONFIAS protocol; CFF: value of the phonemes part of the CONFIAS protocol; CFT: total value of the CONFIAS protocol; ESCALF: subtest of the Cognitive-Linguistic Skills Protocol regarding writing the alphabet in sequence; COPFOR: subtest of the Cognitive-Linguistic Skills Protocol regarding shape copying; CALMAT: subtest of the Cognitive-Linguistic Skills Protocol regarding mathematical calculation; DITPAL: subtest of the Cognitive-Linguistic Skills Protocol regarding word dictation writing; DITPSEU: subtest of the CognitiveLinguistic Skills Protocol regarding pseudo words; REPNU: subtest of the Cognitive-Linguistic Skills Protocol regarding number repetition. 
No correlations were found between FFR examination response for no masking condition and cognitive-language skills.
Table 5 shows the correlation of FFR findings with cognitive-linguistic skills findings in masking condition.

Table 5. Cognitive-linguistic skills correlation matrix with Frequency Following Responses with masking

\begin{tabular}{|c|c|c|c|c|c|c|c|c|c|c|c|c|c|c|c|c|}
\hline & PV & A & PW & PX & PY & $\mathrm{PZ}$ & 0 & CFS & CFF & CFT & ESCALF & COPFOR & CALMAT & DITPAL & DITSPEU & REPNU \\
\hline PV & 1 & $0.003^{*}$ & 0.225 & 0.592 & 0.930 & 0.435 & 0.298 & 0.948 & 0.357 & 0.630 & 0.251 & 0.781 & 0.282 & 0.444 & 0.228 & 0.429 \\
\hline A & $0.003^{*}$ & 1 & 0.423 & 0.906 & 0.066 & 0.667 & 0.246 & 0.946 & 0.457 & 0.747 & 0.130 & 0.913 & 0.349 & 0.250 & 0.262 & 0.407 \\
\hline PW & 0.225 & 0.423 & 1 & 0.175 & 0.978 & $0.003^{*}$ & $0.003^{*}$ & 0.360 & 0.294 & 0.317 & 0.813 & 0.312 & 0.885 & 0.603 & 0.639 & 0.840 \\
\hline PX & 0.592 & 0.906 & 0.175 & 1 & 0.561 & 0.220 & 0.452 & $0.042^{\star}$ & 0.557 & 0.176 & 0.415 & 0.279 & 0.912 & 0.680 & 0.979 & 0.145 \\
\hline PY & 0.930 & 0.066 & 0.978 & 0.561 & 1 & 0.642 & 0.495 & 0.388 & 0.448 & 0.398 & 0.713 & 0.172 & 0.471 & 0.512 & 0.511 & 0.135 \\
\hline $\mathrm{PZ}$ & 0.435 & 0.667 & $0.003^{*}$ & 0.220 & 0.642 & 1 & $0.000^{*}$ & 0.067 & 0.181 & 0.098 & 0.905 & 0.213 & 0.407 & 0.591 & 0.640 & 0.550 \\
\hline 0 & 0.298 & 0.246 & $0.003^{*}$ & 0.452 & 0.495 & $0.000^{*}$ & 1 & 0.358 & 0.642 & 0.471 & 0.347 & 0.543 & 0.790 & 0.664 & 0.682 & 0.202 \\
\hline CFS & 0.948 & 0.946 & 0.369 & $0.042^{*}$ & 0.388 & 0.067 & 0.358 & 1 & $0.000^{*}$ & $0.000^{*}$ & 0.480 & 0.095 & $0.001^{*}$ & $0.000^{*}$ & 0.000 * & $0.004^{*}$ \\
\hline CFF & 0.357 & 0.457 & 0.294 & 0.557 & 0.448 & 0.181 & 0.642 & $0.000^{*}$ & 1 & $0.000^{*}$ & 0.068 & $0.006^{*}$ & 0.000 * & $0.000^{*}$ & 0.000 * & 0.000 * \\
\hline CFT & 0.630 & 0.747 & 0.317 & 0.176 & 0.398 & 0.098 & 0.471 & $0.000^{*}$ & $0.000^{*}$ & 1 & 0.206 & $0.024^{*}$ & 0.000 * & $0.000^{*}$ & 0.000 * & 0.000 * \\
\hline ESCALF & 0.251 & 0.130 & 0.813 & 0.415 & 0.713 & 0.905 & 0.347 & 0.480 & 0.068 & $0.001^{*}$ & 1 & $0.010^{*}$ & $0.003^{*}$ & $0.003^{*}$ & $0.008^{*}$ & $0.003^{*}$ \\
\hline COPFOR & 0.781 & 0.913 & 0.312 & 0.279 & 0.172 & 0.213 & 0.543 & 0.095 & $0.006^{*}$ & $0.024^{*}$ & $0.010^{*}$ & 1 & $0.000 *$ & $0.000^{*}$ & 0.000 * & 0.000 * \\
\hline CALMAT & 0.282 & 0.349 & 0.885 & 0.912 & 0.471 & 0.407 & 0.790 & $0.001^{*}$ & $0.000 *$ & $0.000^{*}$ & $0.003^{*}$ & $0.000 *$ & 1 & $0.000^{*}$ & $0.000 *$ & 0.000 * \\
\hline DITPAL & 0.444 & 0.250 & 0.603 & 0.680 & 0.512 & 0.591 & 0.664 & $0.000^{*}$ & $0.000^{*}$ & $0.000^{*}$ & $0.003^{*}$ & $0.000 *$ & $0.000 *$ & 1 & * & 0.000 * \\
\hline REPNU & 0.429 & 0.407 & 0.840 & 0.145 & 0.135 & 0.550 & 0.202 & $0.004^{*}$ & $0.000^{*}$ & $0.000^{*}$ & $0.003^{*}$ & $0.000 *$ & $0.000 *$ & $0.000^{*}$ & $0.000 *$ & 1 \\
\hline
\end{tabular}

${ }^{*}$ ): Significant difference considering the $95 \%$ confidence interval using Pearson's correlation test.

Captions: Correlation between FFR and cognitive-language skills; Correlation between CONFIAS and the Protocol for cognitive-linguistic skills; PV, A, PW, PX, PY, PZ, 0 - Positive and Negative Peaks of Frequency Following Responses; CFS: value of the syllables part of the CONFIAS protocol; CFF: value of the phonemes part of the CONFIAS protocol; CFT: total value of the CONFIAS protocol; ESCALF: subtest of the Cognitive-Linguistic Skills Protocol regarding writing the alphabet in sequence; COPFOR: subtest of the Cognitive-Linguistic Skills Protocol regarding shape copying; CALMAT: subtest of the Cognitive-Linguistic Skills Protocol regarding mathematical calculation; DITPAL: subtest of the Cognitive-Linguistic Skills Protocol regarding word dictation writing; DITPSEU: subtest of the Cognitive-Linguistic Skills Protocol regarding pseudo words; REPNU: subtest of the Cognitive-Linguistic Skills Protocol regarding number repetition.

No correlations were verified between FFR results for masking condition and cognitive-language skills.

Significant correlations were verified between CONFIAS skills performances assessment and Protocol for Cognitive-Linguistic Skills, suggesting development connection in such skills and reinforcing predictive values of those tests.

\section{DISCUSSION}

Forward masking was observed through increased wave latencies on both transient and sustained portion of FFR assessment, at noise 4 milliseconds before the speech stimulus as compared to condition in quiet. Waves with highest latencies belonged to the transient portion of the stimulus response $(\mathrm{V}=6.97 \mathrm{~ms} \times 7.99 \mathrm{~ms}$; $A=8.44 \mathrm{~ms} \times 9.64 \mathrm{~ms}$ ), suggesting that sustained portion changed less by presence of noise.

Significant increases in latency values in masking condition, especially for waves $V$ and $A$, may be due to reduction in neural synchrony of the transient portion coding ${ }^{16}$. When presenting /da/ syllable in noise and in quiet, in children aged 8-13 years with typical development, the sustained portion was less changed as compared to the transient portion ${ }^{14}$. Similar latency values were found here for condition without masking in the transient portion $(V=6.61 \mathrm{~ms} \times 7.51 \mathrm{~ms}$; $A=7.14 \mathrm{~ms} \times 8.38 \mathrm{~ms}$ ).

On the other hand, latency values for without masking condition found were slightly increased in comparison somewhere else ${ }^{17,18}$, considering that all studies were conducted with native typically developed children aged 6-10 years. These differences may have occurred due to: (i) differences in stimulus parameters, such stimulus presentation rates and number of collected sweeps; (ii) differences between subjects, such as level of language experience, children's behavior during assessments and socioeconomic variations. Also, speech stimuli require different coding of the auditory brainstem, possibly due to the acoustic complexity of speech, with more complex processing of the auditory brainstem ${ }^{19,20}$.

For example, it was observed that children with typical development ${ }^{15}$ showed significant differences in FFR responses between 5-12-year-old children compared with 3-4-year-old children. The investigation 
observed that among children aged 5-12 years, there were no significant differences in FFR responses, especially in transient portion. However, there were significant differences when comparing the group in the 5-12-year group with the 3-4-year group. These findings indicate maturation of the auditory system for speech stimulation from 5 years of age ${ }^{21}$, whose latency values were similar to those found in adults without hearing impairment ( $V=6.68 \mathrm{~ms}$ and $A=7.62 \mathrm{~ms}$ ).

Young children and preschoolers perceive speech in noise with more difficulty when compared to older children and adults ${ }^{17}$. Several factors may contribute to young children's lower performance in noise, such as reduced attention, high internal noise and lower linguistic and phonemic exposure ${ }^{22}$. Those factors may be the reason why speech sound neural coding has not been fully refined and/or accurate, so that young children have a delayed and/or less accurate neural response time when coding relevant acoustic elements for speech, highlighting their difficulties in perceiving speech in noise ${ }^{17,19,20,22}$.

The more the child develops cognitively and biologically, the more they improve their speech perception in noise ${ }^{17}$. At brainstem level, neural response time to speech stimulation does not develop gradually over years, but is abruptly reached at 5 years when biological mechanism of speech perception in noise significantly improves, may be due to neural coding refinement with language experience, since at this age most children experience broader linguistic exposure with literacy beginning ${ }^{20,22}$.

Regarding speech understanding in noise, results presented here were similar to what was previously described, when perception of speech in noise did not vary significantly among children aged 6 to 9 years. This is to say that at 5 years of age, the auditory brainstem for speech sounds is developed, and FFR responses remain stable over time ${ }^{19}$.

The significant differences observed in phonological awareness values across school years of literacy stage revealed an improvement in each year of the literacy stage, with the great increase from the first year to the third year, and from the second year to the third year. No significant differences were observed from the first year to the second year both in phonological awareness and cognitive-language skills.

Phonological awareness is a language skill precursor of literacy and should therefore be developed before the first year of literacy stage ${ }^{23}$. In this study, although a significant advance for this ability was verified, due to the progress in the school year, according to CONFIAS test, this advance was below expectations, as all parameters of the test were based on four-year-old children who were at developmental stage of pre-syllable writing. These results were also found ${ }^{23}$, and this language ability was likely to have been failed in stimulation in the period of early childhood education.

According to Protocol for Cognitive-Linguistic Skills, children ins literacy stage achieved superior and average performance in the third year for word and pseudonym dictation, lower performance for mathematical calculation, and superior performance for number repetition and writing from alphabet.

In this study, all years of literacy stage had superior performance in alphabet writing, and no significant differences were identified across years. All classrooms of school contained the alphabet arranged on the wall, and at the time of assessment, the children only made a copy, without demonstrating any learning in this skill.

For mathematical calculation, all years of literacy stage underperformed. The same result was found for pseudo words dictation and dictation of words, which predominated in the first and second year. These findings revealed that none of the years of literacy stage was able to achieve the expected performance in cognitive-language skills ${ }^{24}$, since even with advances during literacy stage, those advances were below expectations, this may be a warning for developing strategies and research to try to solve this learning deficit in literacy stage.

The analysis of the relationship between FFR and cognitive-linguistic skills during literacy stage, no significant correlations were found. Even considering that during this school period there were advances from one year to the next, observed through significant differences in language skills and phonological awareness among the studied years, these advances did not influence FFR assessment responses, which remained constant during literacy stage, regardless of presence of noise.

These results suggest that cognitive-language skills, important for early reading and writing learning in literacy stage, and speech perception in noise had overlapping neural correlations or connections, but also independent in the auditory brainstem ${ }^{25}$.

Studies carried out in children with reading difficulties and changed auditory processing showed deficits in speech coding in noise in brainstem as compared to children with typical development ${ }^{25}$. While 
cognitive-language skills were shown to be related to speech perception in noise in children with learning difficulties in literacy stage ${ }^{17,25}$, the results in this study did not support this relationship in children with typical development ${ }^{25}$.

The lack of relationship between cognitive-language skills and speech perception in noise in children with typical development in literacy period may be explained due to the fact that literacy skills mature as a function of socio-educational experiences throughout literacy stage, and speech perception in noise is more related to maturation process of the auditory system and neural synchrony, necessary for auditory processing ${ }^{24}$. However, there is a correlation between cognitive-linguistic skills and phonological awareness in literacy period, and poor performances obtained cannot be justified due to tests, but rather to the socioeducational experiences in literacy period.

Synchronic neural discharge in auditory midbrain is required to encode speech characteristics, especially in adverse listening. A break in this neural synchrony will result in auditory processing difficulties for speech perception in noise, which may explain the difference in the relations of speech perception in noise in literacy stage of children with learning disabilities in comparison with children with typical development?

Thus, although FFR with speech stimulation were unrelated to the development of cognitive-language skills in children with typical development, they may assist in the diagnosis of language disorders, and in tracking learning disabilities by enabling early interventions and training in changed auditory skills, ensuring better performance of school children. Therefore, further studies should be conducted to analyze FFR with socioeconomic characteristics and impairment language and auditory processing disorders.

\section{CONCLUSION}

This study showed no relationship between forward masking and cognitive-language skills in children, as a function of literacy stage. The relationship between auditory processing development skills and language development was highlighted.

\section{REFERENCES}

1. Skoe E, Kraus N. Auditory brainstem response to complex sounds: a tutorial. Ear and Hearing. 2010;31(3):302-24.
2. Bayat A, Farhadi M, Emamdjomeh $H$, Saki $N$, Mirmomeni G, Rahim F. Effect of conductive hearing loss on central auditory function. Braz. J. Otorhinolaryngol. 2017;83(2):137-41.

3. Anderson LA, Linden JF. Mind the gap: two dissociable mechanisms of temporal processing in the auditory system. J. Neurosci. 2016;36(6):1977-95.

4. Berti LC. Desempenho perceptivo-auditivo de crianças na identificação de contrastes fônicos. Alfa, R. 2017;61(1):81.

5. Villega CCS, Berti LC. Desempenho perceptivo auditivo de crianças na identificação de contrastes fonológico entre as fricativas. RABRALIN. 2016;15(3):205-26.

6. Bertachini AL, Pupo AC, Morettin M, Martinez MAN, Bevilacqua MC, Moret ALM et al. Frequency Modulation System and speech perception in the classroom: a systematic literature review. CoDAS. 2015;27(3):292-300.

7. White-schwoch T, Carr KW, Thompson EC, Anderson S, Nicol T, Bradlow AR et al. Auditory processing in noise: a preschool biomarker for literacy. PLoS biology. 2015;13(7):1002196.

8. Vilela N, Wertzner HF, Sanches SGG, Neves-Lobo IF, Carvallo RMM. Processamento temporal de crianças com transtorno fonológico submetidas ao treino auditivo: estudo piloto. J Soc Bras Fonoaudiol. 2012;24(1):42-8.

9. Vellozo FF, Schwantes AL, Souza AEH, Peixes BP, Biaggio EPV, Martins QP et al. Temporal resolution in elderly. Rev. CEFAC. 2016;18(2):355-61.

10. Betti T, Bruno RB, Oppitz SJ, Bruckmann M, Garcia MV. Melodic pattern test of temporal processing: an analysis of different types of responses. Audiol. Commun. Res. 2016;21:e1666.

11. Filippini R, Schochat E. A new paradigm for temporal masking assessment: pilot study. CoDAS. 2014;26(4):302-7.

12. Hodge SE, Menezes DC, Brown KD, Grose $\mathrm{JH}$. Forward masking of the speech-evoked auditory brainstem response. Oto. Neurotol. 2018;39(2):150-7.

13. Mehraei G, Gallardo AP, Shinn-Cunningham BG, Dau T. Auditory brainstem response latency in forward masking, a marker of sensory deficits in listeners with normal hearing thresholds. Hear. Res. 2017;346:e 34-44. 
14. Moojen S, Lamprecht R, Santos RM, Freitas GM, Brodacz R, Siqueira M et al. CONFIAS Consciência Fonológica: Instrumento de Avaliação Sequencial. São Paulo: Casa do Psicólogo, 2003.

15. Capellini S. Protocolo de Avaliação de Habilidades Cognitivo-Linguísticas: livro do profissional e do professor. Riberião Preto, SP: Booktoy, 2017.

16. Sanfins MD, Borges LR, Ubiali T, Donadon C, Diniz TAH, Hatzopoulos $S$ et al. Speech-evoked brainstem response in normal adolescent and children speakers of Brazilian Portuguese. Int. J. Pediatr. Otorhinolaryngol. 2016;90:e12-19.

17. Thompson EC, Carr KW, White-Schwoch T, Otto-Meyer S, Kraus N. Individual differences in speech-in-noise perception parallel neural speech processing and attention in preschoolers. Hear. Res. 2017;344:148-57.

18. Mamo SK, Grose JH, Buss E. Perceptual sensitivy to, and electrophysiological enconding of, a complex periodic signal: effcts of age. Int $\mathrm{J}$ Audiol. 2019;58(7):441-9.

19. Hornickel J, Knowles E, Kraus N. Test-retest consistency of speech-evoked auditory brainstem responses in typically-developing children. Hear. Res. 2012;284(1-1):52-8.

20. Meng Z, Zheng Y, Wang K, Li D. Evaluation of speech perception in competing noise conditions for normally hearing children. Noise Health. 2013;15(64):178.

21. Song JH, Skoe E, Banai K, Kraus N. Training to improve hearing speech in noise: biological mechanisms. Cereb. Cortex. 2011;22(5):1180-90.

22. Martins CIS, Queiroga BAMD, Rosal AGC, Cordeiro AA. Comparative analysis of cognitive-linguistic evaluation in normal hearing schoolchildren and users of cochlear implants. CoDAS. 2018;30(4):e20170133.

23. Rosal AGC, Cordeiro AAA, Silva ACF, Silva RL, Queiroga BAMD. Contributions of phonological awareness and rapid serial naming for initial learning of writing. Rev. CEFAC. 2016;8(1):74-85.

24. Tichko P, Skoe E. Musical experience, sensorineural auditory processing, and reading subskills in adults. Brain Sci. 2018;8(5):77.

25. Bonacina S, Krizman J, White-Schwoch T, Kraus $\mathrm{N}$. Clapping in time parallels literacy and calls upon overlapping neural mechanisms in early readers. Ann. N. Y. Acad. Sci. 2018;1423(1):338-48. 